\title{
Entrepreneurial Agency and Field Relations: A Realist Bourdieusian Analysis
}

\section{Steve Vincent and Victoria Pagan (Newcastle)}

Accepted for publication, pending minor revisions, in Human Relations

\begin{abstract}
This paper combines theoretical resources from Bourdieusian and critical realist scholarship to explore qualitative data about the networking practices of 25 self-employed and entrepreneurial human resource consultants. The analysis, which concentrates on a regional economic field in the UK, assesses (i) how the field was structured to support entrepreneurial careers (socio-economic structure) and (ii) how these consultants differentially enacted and experienced relations within this field (entrepreneurial agency). Concepts taken from critical realism are used to deconstruct the field in terms of its constituent parts, or field elements, and concepts taken from Bourdieu are used to reconstruct these parts in terms of their resources and local agential struggles. Field elements were also analysed in terms of their (critical realist) institutions and (Bourdieusian) doxa, and in terms of (Bourdieusian) habitus and (critical realist) reflexive imperatives. We argue that the form of analysis which develops, which we call Realist Bourdieusian Analysis, reveals more about the causal properties of the field than forms of analyses that are limited to the Bourdieusian lexicon, and so additions from critical realism enrich our understanding of fields and, agents' relations and experiences within the field. More specifically, the analysis reveals a field constituted of a complex normative geography, which consultants navigate through reflexive struggles in relation to a range of field elements with which they were engaged. The analysis concludes by highlighting the practical, theoretical, methodological contributions of this research.
\end{abstract}

\section{Keywords}

Bourdieu, critical realism, reflexivity, self-employment, professional work, networks, networking 


\section{Introduction}

This paper asks whether and how the usefulness of Bourdieu's theory of practice might be extended by situating it within a critical realist ontology, and we argue this creates the possibility of various novel insights that may be overlooked by analyses which read Bourdieu too narrowly. The theoretical synthesis proposed emerged from an iterative process with which the authors engaged as they struggled to understand and explain a qualitative dataset. The data comprises interview transcripts with 25 respondents who were self-employed and entrepreneurial human resources (HR) consultants. They lived and worked around a conurbation in the North of England. Respondents were asked about (i) the properties of the regional economic field they worked in, and, (ii) how they engaged with this field as they developed their businesses. These lines of questioning, we hoped, would enable contributions to knowledge of regional supports to entrepreneurial careers (see also Woolcock, 1998; Woolcock and Narayan, 2000; Malecki, 2012) and to the enhancing our understanding of the lived experiences of skilled self-employed workers in a networked society (see also Castells, 1996; Wittel, 2001).

The strength of Bourdieusian theory is that it demonstrates both structure and movement within structures; that structures influence individual thought and action and that individuals also replicate/create or transform these structures (Sallaz and Zavisca, 2007). However, as we explored these areas, we found Bourdieusian middle-range concepts (e.g.forms of capital), or those which illuminate the spaces or phenomena between the macro (field) and micro (habitus) levels of analyses, less precise for interpreting our respondents' descriptions of the setting and their experiences within it. Consequentially, and as one of the authors had a background in Critical Realist Scholarship (CRS), we found ourselves borrowing and incorporating concepts and methods developed within this alternative, if in many ways complimentary, theoretical lexicon.

In relation to (i), the properties of the economic field, we found CRS middle range categories (taken from Fleetwood, 2015) useful for deconstructing the regional field that our respondents described in terms of its constituent parts - henceforth field elements or the things the field contains. We then assess these field elements in terms of the resources (forms of capital, Bourdieu, 1986) the respondents embodied, used, accessed, transformed and 
exchanged (etc.) in their relations. As will be seen, opportunities for business and network development could be more formal or informal, periodic or sporadic, organised or ad-hoc, resulting in social relations of different forms and intensities, which also related to distinctive types of resources (e.g. skills, information, products, tools, clients, etc.). Consequentially, drawing on a broader range of middle range categories was enabling as it facilitated the discovery of the causal parts (field elements) of the regional economic field studied and how these were nested and interrelated.

In relation to (ii), the experience of skilled entrepreneurial careers in a networked society, we found CRS analytical methods (taken from Archer, 2003, 2010, 2012) useful because they encourage analyses to separate the properties of the context from the projects of the people who act within it. We found this separation useful for understanding the reflexive struggles described by by respondents, how these emerged from relations with field elements, and how these struggles also contributed to the nature of the setting, as a distinct field (see also Bourdieu and Wacquant, 1992). As will be seen, respondents were keen to defend their reputations and approaches to business practice, and so their reflections on their practices positively represented, and reflexively defended, the nature of their own engagement with field elements, whilst they could also be disparaging about the alternative approaches that other consultants took (see also Sayer, 2005).

Finally, and as we also found CRS analytical methods a useful addition to our Bourdieusian framework, we subsequently drew from recent contributions to CRS methodology (see Edwards, et al., 2014) when designing and executing the analysis. The outcome, we argue, offers a more complete and compelling method for assessing regional supports to entrepreneurial careers, and entrepreneurial experiences within regional economic fields. We also argue that this method can be transposed to analyses of other regional fields and different cadres of entrepreneurial agent.

The paper is structured as follows. The theoretical review, which follows this introduction, outlines Bourdieu's theory of practice. Existing Bourdieusian contributions to entrepreneurship research are reviewed, and this review is used to substantiate our claim: that moving Bourdieusian scholarship towards CRS results in novel insights that contribute to research on entrepreneurial careers. An alternative methodology, which takes account of CRS categories and analytical methods, is then introduced, and the data is presented in line with 
the new analytical method proposed. A discussion then reflects on the usefulness and general applicability of the analytical method proposed, before conclusions are then drawn.

\section{Bourdieu's theory of practice}

Bourdieu's lexicon remains, for good reason, widely used and celebrated. In the academic field explored in this paper, self-employment and entrepreneurship studies, his work has been used to explore migration (Vershinina et al., 2011; Nowicka, 2013); class (Anderson and Miller, 2003); learning (Karataş-Özkan, 2011); culture (Spigel, 2013); rural economies (Sutherland and Burton, 2011); philanthropy (Shaw et al., 2011); and gender (Marlow and Carter, 2004; Vincent, 2016). Arguably, his framework is broadly applicable because it allows for deconstruction and reconstruction of the social world via core concepts: fields, the variously textured social environments we navigate; capital, the economic, cultural, social and symbolic resources of value in these social environments; and habitus, the "system of dispositions" (Bourdieu, 1984:2) that affects agency within fields. In this framework, fields represent macro-level environments. Habitus represents the micro-level of personal proclivities and deportments. Forms of capital offer a middle-range, which disaggregates fields in terms of the resources they contain and prioritise, and so offers connection of fields with habituses. It is this connective tissue, the middle-range between the macro and micro, which, we argue, benefits from a movement towards CRS.

\section{Forms of Capital}

For Bourdieu, people use various resources, or forms of capital, to extend their interests. Economic capital is universally transposable via money and can be derived from assets (material resources, cultural artefacts, patents, etc.) or remuneration (pay), or extracted in the form of profits (drawings, dividends, etc.). For Bourdieu (1986), all forms of capital can be derived from economic capital, but only with time and effort in transformation: we can pay for our schooling and connections, for example, but money facilitates the access, not the outcome.

Cultural Capital exists in three forms (Bourdieu, 1986: 243). Firstly, it can be embodied, for example, as 'long lasting dispositions of the mind' and as skills/abilities. Secondly, it can be objectified as cultural goods, such as pictures, books, tools and machines, which must be made and which have differential value according to contexts. Third, it can be 
institutionalised, such as within the education and qualifications systems. It thus includes, inter-alia, abilities, artefacts and formal institutions, which should be evaluated in fieldspecific ways. Cultural capital can be individual and also collective, such as when there is normative agreement about the positive evaluation of cultural 'goods'. Objectified cultural goods, such as artwork or technologies, can be traded as commodities. Institutionalised cultural capital, such as qualifications arrangements, emerge from the schooling system and qualifications authorities, and so are structured within field relations. Cultural capital is thus heterogeneous and ontologically various.

Social capital is constituted of resources that can be obtained from 'a durable network of more or less institutionalised relationships of mutual acquaintance and recognition' (Bourdieu, 1986: 251). The concept has been widely deployed, often without Bourdieu's other concepts, to study entrepreneurs and their environments (see Woolcock and Narayan, 2000; Westlund and Bolton, 2003; Cattell, 2004; Malecki, 2012). Like cultural capital, social capital is heterogeneous and ontologically various. The specific form it takes depends on the other resources it relates to, and, consequentially, analyses have distinguished between several types of social capital (see Lin, 2008; Coradini, 2010). The sharing of more valuable forms of objectified cultural capital and the development of expertise (embodied cultural capital), for example, is associated with long-lasting cooperative relationships between more homogeneous social agents who trust one another and so more willingly pool resources (see Adler and Kwon, 2002). In contrast, more inclusive types of association, which tend to operate across broader social formations and amongst more heterogeneous agents (see also Granovetter, 1973), are associated with more favourable access to information (viz cultural capital) which is likely to result in the development of novel activities and practices (see Burt, 2005). For the purposes of this paper, a distinction is made between deep social capital, which implies trust and pooling or risking of personal resources, and shallow social capital, which implies less commitment and/or personal resource risking.

As with cultural capital, forms of social capital emerge from or operate at various levels (families, firms, communities, regions etc.). These middle-range forms may have a good deal of solidarity (see Bourdieu, 1986) or social capital supporting institutions and cultures (see Westlund and Bolton, 2003), or these supports may be lacking. Forms of social capital can be fostered by civic engagement, investments in education and developing predicable and benevolent institutional arrangements (see Woolcock, 1998; Putnam, 2000). However, they 
can also diminish because of corruption and malpractice (see Woolcock and Narayamn, 2000). For example, deeper forms of social capital may be good for exchanging opportunities and know-how, but they are also associated with cronyism and a failure to innovate beyond an in-group (see Adler and Kwon, 2002). Likewise, shallower connections can be exploited if one side of the relationship has little at risk, such as where or 'structural holes' (see Burt, 2005) and bounded rationality (see Williamson, 1986) are used to obtain disproportionate personal gains.

Finally, symbolic capital is prestige and legitimacy, "distinction" (Bourdieu, 1985: 731) derived from being identified as having the right forms of capital in the right volume to succeed within a field according to its rules (Bourdieu and Wacquant, 1992). It is therefore identified in terms of the recognition of other forms of capital. This legitimacy, then, facilitates access to resources via "favours" and other positive forms of recognition (see Bourdieu, 1990: 118-119). Those with the greatest volume of symbolic capital are more able to determine this vision or the "official point of view" (Bourdieu, 1989: 22), which confirms authority and ability to authorise history, affirming what people must do (order, prescriptions, directions), and defining as fact what people have done (Bourdieu, 1989).

For Bourdieu (1986) as forms of capital are activated they are converted and developed. In other words, the power of capital, as deployed over time, is observed in levels or amounts of capitals that subsequently accrue (see also Lin, 2008). We know, for example, that, in entrepreneurial careers, social capital is fostered to access economic capital, or remuneration and work opportunities (see Barley and Kunda, 2004), and cultural capital, or new skills (see Adams and Demaiter, 2008). It is thus through the strategic deployment of capitals within the field that itinerant experts increase their overall stocks of resources (see also Özgilbin and Tatli, 2005; Drakopoulou-Dodd et al., 2014). Forms of capital are thus intimately interconnected and mutually constituted in heterogeneous and ontologically various ways. However, given the limited number of forms of capital, developing an analytical framework that summarises forms of exchange is straightforward (see Table One). This framework is taken forward and used to analyse elements of the field studied. Symbolic capital has been omitted from the framework as it emerges from recognition of other forms. Instead, it will be highlighted, in passing, where its development or used appeared to be significant. 


\section{INSERT TABLE ONE ABOUT HERE}

In the following, we argue that the heterogeneous and ontologically various constitution of Bourdieu's forms of capital encourages researchers to move too quickly from the macro to the micro. The movement is from field (of power/capital) to habitus (as enabled by the capital at the agents' disposal). In our opinion, this limits insights into the independent causal properties of the field, which is left as a heterogeneous and ontologically diverse backdrop. To understand this argument, further unpacking of the concepts habits and field is needed.

\section{Habitus}

Habitus is typically tacit and subconscious, internalised, via socialisation and enculturation. Habitus thus represents agents' affectivity in terms of their sense and understanding of the legitimacy of the specific contest for capitals that agents are engaged with. Some argue the concept underplays the role of conscious deliberation in human action (Jenkins, 2002; Elder Vass, 2010). In Bourdieu's words, habitus “can be objectively adapted to their outcomes without presupposing conscious aiming at ends of an express mastery of the operations necessary in order to attain them" (Bourdieu, 1990: 53). Additionally, however, his concept of reflexivity offers a way for social actors to consider their own social positions, potentially provoking habitus and field change (Bourdieu, 1994). Bourdieu's work suggests that there is constant transformation, albeit towards either: 1) reinforcement and repetition, wherein any movement is still within the bounds of conformity; or 2) towards deeper change, which requires the deployment of higher levels of reflexivity.

However, the potential for theoretical circularity is also apparent in Bourdieu's discourse: fields impel habituses and habituses structure fields. This circularity is reflected in Bourdieusian analyses, which can fail to analytically separate the properties of the field from the properties of agents (habitus). De Clercq and Voronov's (2009) Bourdieusian analysis of entrepreneurs, for example, asserts: 'identities and external environment get jointly and simultaneously co-created' (297). Consequentially, Archer (2010) accuses Bourdieusian analyses of central conflation, arguing that his lexicon is incapable of separating the independent causal influence of the parts of society (i.e. fields and field elements) from those of the people (agents) who constitute it. For those committed to CRS, this is analytically 
unhelpful: we need to find ways to delineate the independent influences of the field and the social agents, whose projects are variously engaged with them.

\section{Field}

For Bourdieu, different fields contain distinctive species of capital. For example, the forms of capital needed to succeed in a field where musicians play (see Scott, 2012) are very different from those needed to compete in a field where HR practitioners consult (see Vincent, 2016). The distribution of capitals affects objective relations between positions across fields by compelling agents and institutions. Access to forms of capital thus allows 'access to the profits that are at stake in the field, as well as their objective relations to other positions (domination, subordination, homology, etc.)' (Bourdieu and Wacquant, 1992: 97). Fields thus contain both distinctive forms of capital, which are contested locally, and objective (i.e. external) power relations (borne of forms of capital) that act on and through the individuals who constitute them.

Finally, fields also have doxa, or rule systems that may remain unchallenged, as "[s]ystems of classification that produce, in their specific logics, the objective classes [...] or positions in relations of production" (Bourdieu, 1977: 164). However, and as will be seen, these rule systems are subject to negotiation and challenge by reflexive social agents, so field and habitus are intimately related, as one side "is a relation of conditioning: the field structures the habitus [whilst] the other side, it is a relation of knowledge or cognitive construction" (Bourdieu and Wacquant, 1992: 127, emphasis as original).

Analyses of the constraints fields impose on agents is surprisingly limited in existing Bourdieusian research on self-employment and entrepreneurial careers (cf. Vincent 2016). Relevant theoretical reviews, for example, pay only passing attention to the field (De Clercq and Voronov, 2009; De Clercq and Honig, 2011; Spigel, 2013). De Clercq and Voronov (2009), who, at least, have a dedicated a two-paragraph section on the concept, described the field as variously demarcated and/or hierarchical arenas of struggle or 'competing logics' (399). Spigel (2013) is similarly parsimonious, defining field as 'historically produced social spaces of rules, traditions and power relations' (808). Empirical studies appear similarly sparse. Lee and Shaw's (2016) study of new-firms defines it, briefly, as spaces on which actors 'acquire the variety of forms of capital needed to secure dominant positions within the 
'fields' (social, institutional and market) in which they operate' (4). Karataş-Özkan (2011) define the field studied loosely, as 'enterprise culture discourses in the UK and dynamics of creative industries' (882) and 'the dynamic area in where human agents struggle to accumulate different species of capitals that will influence their position' (884).

In the few Bourdieusian studies of entrepreneurship which take a regional perspective (Nowicka, 2013; Spigel, 2013), the concept is also minimally deployed. Spigel (2013) spends considerably more time unpacking 'entrepreneurial cultures' than field. Nowicka's (2013) analysis prioritises the notion of 'social position' within the field, rather than the field as a thing in itself. She is even more diminutive in her definition of field, suggesting that the concept is 'primarily metaphorical' (32), and so must offer limited access to causal efficacy of enduring social formations.

In our view, Bourdieusian scholars may fail to engage fully with the concept of field because the forms of capital framework, Bourdieu's middle range, is rather less good for systematic deconstructing the field in terms of its constituent parts, or field elements. In other words, his theory lacks consistent concepts to identify the sub-structures, arrangements, articulations, mechanisms, organisation, institutions (etc. etc.) of fields and how these are also constituted of specific types of agential relations (people, resources and practices). Consequently, Bourdieusian scholars must either ignore the causal properties of this middle range, despite its apparent import within the forms of capital framework, or they must find their own way to deconstruct and reconstruct elements of the field, to identify and analyse them. We further argue that this de/reconstruction work is rendered even more difficult if one assumes the field and habitus are simultaneously co-created, as this rather obscures the imposition that middlerange phenomena make on the relations between the two. In the following section, we propose a synthesis of CRS and Bourdieusian theory that, we argue, facilitates and assists this deconstruction and reconstruction work.

\section{Realist concepts and Bourdieusian research}

In the following, we argue that Bourdieu is not as guilty of central conflation as Archer (2010) protests, but that the Bourdieusian lexicon can be strengthened with a movement towards CRS. As demonstrated above, species of capital emerge within heterogeneous and ontological various phenomenon (school systems, clubs, legal frameworks, discourses and rules, objects and artefacts, etc. etc.), and so concepts and methods that help identify these 
field elements are, potentially, analytically useful for identifying the determinations that fields impose. We argue that this is where CRS can help.

Bhaskar (1993) uses the metaphor laminated system to describe the relations between the heterogeneous and ontologically various elements of all natural and social orders. The concept thus transcends notion of field. These laminated systems, whether natural or social, are not sealed, but layered or hierarchically organised open-systems of interacting entities. For Bhaskar (1979, 2008), all entities have their own irreducible causal powers and properties. Schools and businesses, for example, are social entities (agencies or organisations) that accomplish outcomes (mass education and production) that their parts (individual classrooms, pupils, teachers, factories, employers, workers, etc.) cannot accomplish in isolation. Entities and classes of entity are thus rendered distinctive in terms of the specific powers and properties they possess, their essences (see O’Mahoney, 2012).

Arguably, the powers and properties or essences of social entities (agencies and organisations) can be efficiently worked-out in terms of the resources (forms of capital) which shape their internal (and external) relations. Schools are constituted of specifically resourced classrooms, pupils and teachers (etc). Business are constituted of specifically resourced units of production (teams, factories, etc.), employers and workers (etc.). These resource-based constitutions affect outcomes, such as levels of student attainments or rates of production. Furthermore, schools and businesses also reside within 'higher-level' fields (viz laminated systems): schools reside within the field of education; businesses reside within economic fields. It is their specific relations with other entities within these laminated system (i.e. their relations with regulators, governments, competitors, etc.) that affect the specific emergence of elements of field. Overall, the powers and potentials of social entities (agencies and organisations), which can be known in terms of the resources they contain, thus combine and interact, across levels, to form the generative structures or causal mechanisms that impels emergent patterns in events within fields (viz laminated systems).

For the purposes to this paper, we draw on Fleetwood (2015), who develops the CRS lexicon in a way that facilitate the further disaggregation of fields and field elements. He suggests fields can be explored in terms of their their respective social structures, organisations, mechanisms, and institutions, each of which is explored in the following. 
Social structures are 'latticeworks of internal relations between entities [agents/agencies] that may enable and constrain (but do not determine) the plans and actions of agents who reproduce and/or transform these relations" (Fleetwood, 2015: 95-97). We use this concept to refers to types of relation between specific types of agent, such those of employers and workers, teachers and pupils, sub-cultures, races, genders and/or classes that often interact as they transcend fields (viz laminated systems). Using this term allows researchers to examine which types of relation constitute the field studied, and to study these relations terms of the resources (forms of capital) and resource exchanges through which they can be known.

Organisations identify middle-range field elements (i.e. agencies) that are both entities and 'special institutions' (see also Hodgson, 2006). They have boundaries to establish membership; forms of internal sovereignty within jurisdictions; and, defined roles and responsibilities, which are often consciously designed. They contain their own habitus of implicit (norms, values, preferences) and explicit (rules, codes, laws) institutions, which govern their conduct. They are 'things in themselves' that act independently within fields in terms of their own constitutions (see also Bourdieu, 2005: 205). We can, then, consider how organisations shape flows of resources by identifying: which types of organisation are agents engaged with in a local field; what forms of resources can be accessed, developed and exchanged within these organisations; and, how engagement with these organisations is reflexively evaluated and contested.

Fleetwood uses a second middle-range concept, mechanism, as a catchall for specific or identifiable relational field elements, which are neither organisations nor reducible to the actions of an individual. Whilst the term is seldom used by Bourdieusian scholars (cf. Bebbington, 2007), in CRS the term is used to identify specific, enduring and distinctive causal assemblages or relational forms (see also Elder Vass, 2010). Mechanisms can have greater or lesser degrees of permanence. Amongst entrepreneurs, for example, they may emerge from the properties of relatively fleeting dyadic contractual relations between individuals or they may inhere within small groups who 'work together' over longer periods of time (see below). They may be within organisations, such as human resources 'architectures' (see Lepak and Snell, 1999), or between them, as specifically constituted inter-organisational relations (see Vincent, 2005). More generally, and for the purposes of this paper, they are 'systematic configurations' (Fleetwood, 2015: 97) of agents, enacting institutions (norms, rites, customs, habits, etc.) in relations with other entities (people, 
artefacts, materials, organisations etc.) in ways that affect and, potentially, transform resources (and relations) independently of other phenomena. We can, then, consider which types of mechanisms agents are related through within the field studied; what forms of resources can be accessed, developed and exchanged within these mechanisms; and how engagement with these mechanisms is reflexively evaluated and contested by participants.

Finally, the concept, institutions, refers to a micro-level of customs, rules, mores, norms, obligations, rituals, and values (etc.) and so corresponds to Bourdieu's concept doxa. We recognise that the term, institution, is used to refer to a variety of phenomenon (customs, mores, rules, etc.), and therefore needs further development. However, as the aim of this paper is to demonstrate the usefulness of CRS to Bourdieusian scholarship, we do not undertake this task here. Instead, we take it at "face value" that institutions (doxa) constitute a foundation or micro-level of rules, customs (etc.) which condition the emergence of 'higher level' field elements (mechanisms, organisations, social structures), and that institutions often become habituated and rooted in the nervous system - i.e. as tacit, subconscious, affective (Fleetwood, 2015) - so they correspond to the "structuring" or subconscious aspects of habitus.

However, whilst we might follow institutions subconsciously or habitually, we can also be reflexive about them. Indeed, Archer (2003) argues forms of reflexivity, or inner conversations, rather than habituses, are the motor of social agency - one way or another, actors always choose which projects that want to pursue, and it is these choices which impel social stability or social change. This does not preclude actors being habitual, as agents are routinely engaged with specific practices (see also Elder-Vass, 2010). Reflexivity and habitus thus emerge in-situ, or in relation to the present circumstance, and their so their forms must be determined empirically. We can, then, explore whether and how agents reflexively contest the field studied, and what this contest suggests about subjective experiences and social relations within the field examined and for tendencies of social stability and change.

We argue that there is considerable overlap and similarity between Bourdieusian and CRS ideas in this area. Both argue that reflexivity about institutions (doxa) is the motor of social change. Archer (2012), perhaps goes furthest, by associating complex modern social realities with reflexivity imperatives. These imperatives emerge because complex social orders (vis fields or laminated systems) typically offer no standard rule systems to guide action, and so 
agents cannot act based on consistent set of institutions, and so reflexivity is inevitably required when deciding what to do. Arguably, a similar point is made in De Clercq and Voronov's (2009) Bourdieusian study, which highlight how successful entrepreneurs must both 'fit in' and 'stand out', as they 'improvise their way through a world that remains in a constant state of flux' (397). Entrepreneurial habitus is thus described as necessarily reflexive, as it often needs to challenge the existing institutions (doxa) to succeed (De Clercq and Honig, 2011). Reflexive struggles are thus critical to overcoming doxa (institutions) which are personally limiting (Bourdieu and Wacquant, 1992), and people are creative as they 'play the game' and can transform how it is played.

\section{Methodology}

Having argued that Bourdieusian scholarship can benefit from a movement towards CRS, we now empirically demonstrate this assertion. Usefully, Bourdieu offers an analytic method for deconstructing the field (see Bourdieu and Wacquant, 1992: 104-105). Analyses should (1) analyse the position of the field studied in relation to other fields and (2) map-out the relations between actors and organisations who compete for the resources (capitals) the field contains. Undertaking these forms of analysis enables scholars to (3) place agents within their contexts, to understand how they behave in relation to this context, and whether they are likely to succeed.

Recent advances to methods from CRS (see Edwards et al., 2014) resonate this approach. Vincent and Wapshott (2014), for example, use CRS to account for 'organisational mechanisms'. They propose a similar analytical staging to Bourdieu, which includes: (1) configurational analysis, to account for the articulation of the specific 'social context' (viz field) and, (2) normative analysis, to account for the 'ideas' (viz inner conversation about institutions) that inform actors' proclivities for action. These two forms of analysis then facilitate (3) field analysis, in which (1) and (2) combine to describe emergent social phenomena.

In both approaches, analytical categories emerge from or are grounded within field specifics. However, unlike traditional approaches to grounded theory, which seeks to bracket off existing theory and base analysis entirely within the categories within the social world examined (see Glaser and Strauss, 1967), theory is essential to construct the social world, as 
both a laminated system of interacting entities and as a field in which specific species of capital are contested. In the following, we extend an analysis that is empirically grounded in the field studied and theoretically grounded in CRS (see also Kempster and Perry, 2014) and Bourdieusian categories (see also Goddard, 2004).

\section{Data collection}

Developing a representative sample proved impossible as there was no single list or register for HR consultants. Most (19) were accessed using a "snowballing" strategy. This strategy, which started with two consultants who were known to the researcher, was useful because it created opportunities to explore social networks from different points of view. Four respondents were identified by 'cold calling' HR consultants who advertised. Two respondents were identified by participating in events organised by the Chartered Institute of Personnel and Development (CIPD), the national professional association for HR managers. Attendance at these meetings also allowed observations of consultants' networking practices.

The sample (17 women and eight men) reflects the gender balance within the industry (see Thwaites and Jennsion, 2006). All but two of the respondents had previously held full-time jobs at managerial grades within the HR profession, which conferred legitimacy. Ten respondents had previously been 'generalist' HR managers, who oversaw and participated in the operational development of a range of HR practices. Seven had oversight roles, as HR directors. Two were specialist trainers. Two were specialist recruiters. One had been a national employment relations manager, and another had been a national training manager. The two respondents who did not have management-level experience within the HR profession claimed legitimacy in other ways. One was a retired policeman who owned an employment law consultancy. The other had been a HR officer and held a Master's-level degree in Human Resource Management. Overall, while it is impossible to say whether this sample is representative of the population, its apparent diversity suggests the dataset is a good opportunity to learn (Stake, 2006).

Interviews lasted between 32 and 90 minutes, with the average being just under an hour. Around 1,500 minutes of conversation were recorded and transcribed, producing over 200,000 words. The interviews were semi-structured to understand the distinct types of 'network' that the respondents were engaged with. Interviewees also discussed how and where they developed their businesses; how and when they engaged with their fields' 
'networking opportunities', and how these were organised; and, how respondents accessed resources from various places within the field. These lines of enquiry enabled configurational analysis, or mapping the relations within and between field elements. Respondents were also asked about their preferences when networking to identify the forms of practice they disliked or favoured less, and why this was the case. These lines of enquiry involved constantly asking 'why' until underlying reasons for engaging with identified field elements emerged. These lines of questioning also encouraged respondents to reflect on their activities and the ideational struggles they were engaged with at work.

The research continued to seek respondents until no new stories were emerging, either about respondents' networking and business development opportunities or about their preferences in these areas. At this point, it was assumed the point of theoretical saturation had been reached, as engagement with the field resulted in very little incremental learning (see Glaser and Strauss, 1967). As the research was informed by CRS, two forms of saturation were considered (see Vincent and Wapshott, 2014). Field saturation occurs when new interviews result in little incremental learning about the objectifiable social formations within the field studied. Agential saturation occurs when new interviews reveal little incremental learning about subjective engagement with the field. Seeking these alternative forms of saturation enables the researcher to analytically separate causal influences, of the parts of the laminated system (viz field) and social agency, as data are collected and analysed.

\section{Data Analysis}

The analysis, which is summarised in Table Two, was undertaken in several stages, although it should be stressed that the analysis was not a simple linear process, but one that oscillated between various middle-range concepts as the authors struggled to reconcile CRS and Bourdieusian concepts. The outcome thus reflects the theoretical assimilation of CRS and Bourdieusian scholarship, developed in the first half of this paper.

In the end, the primary classification system was the identification of field elements, which used Fleetwood's (2015) categories. His middle range concepts - mechanisms and organisations - were used to identify the field elements that respondents described as significant for their own business outcomes. These field elements were then analysed, using Bourdieusian and CRS concepts, in a manner that is hierarchical, building upwards from an economic base, and not arbitrary, because it develops from the theoretical groundwork 
undertaken in this paper. The primary categories for analysing the constitution (and powers) of field elements was Bourdieu's forms of capital framework, although this analysis also identified the social structures that field elements conditioned. The field elements identified were also analysed in terms of the institutions or doxa that they contained, and in terms of the types of reflexive struggles the agents were engaged with as they related with and co-created field elements.

To expedite this analysis, the bracketed italicised numbers and letters, such as (7) (d), are taken from the tables as shorthand to identify the middle-range phenomena within the field studied. This shorthand enables the analysis to be sensitive to the local specificity of the field, whilst also maintaining a links to the theoretical vocabulary we developed to understand it. The following sections thus unpack the Realist Bourdieusian Analysis we developed undertook.

INSERT TABLE TWO ABOUT HERE

\section{Mechanisms}

The respondents' descriptions of their working practices suggested two types of mechanisms were significant elements of the field studied: contractual mechanisms and relational mechanisms. The following sections explain these mechanisms and how they were related, the capital exchanged through them, the institutions on which they were based and the reflexive struggles entrepreneurial agents engaged with as they related to them.

\section{Contractual Mechanisms}

Respondents accessed economic capital via two types of contractual mechanism: first, contracts with clients, through which HR consultants traded on cultural capital, in the form of services, for fees $(4,7)$, and second, referral fee payments were mechanisms through which they traded between social capital and economic capital, or fees $(3,10)$. Both involved compliance with (institution/doxa) and advocacy for various forms of contractual relationships between parties to economic exchanges: the righteousness of these forms of exchange was seldom questioned, although, as we shall see, the legitimacy of specific manifestations of these mechanisms was a matter for struggle. 
(a) Contracts with clients were variously constituted. Most of the respondents (16 of the 25) developed long-term relationships with a variety of small- and medium-sized enterprises (SMEs) which, typically, did not employ HR professionals. Respondents sold HR services, such as writing basic policy documents, helping with recruitment and dealing with disciplinary issues, to these clients in exchange for fees (4), and having relationships with a range of SMEs resulted in a steady flow of repeat business, which maintained incomes. Contracts were typically organised around 'day rate' norms (institution/doxa), which appeared to reflect the consultants' previous experiences (embodied cultural capital). Dayrates of $£ 300$ were "normal". Only a few respondents, with less experience, charged less than around $£ 300$, and only a few respondents, who had more senior roles prior to becoming selfemployed, charged more.

Higher status work, which related to larger contracts with higher day rates (4), typically came from larger clients. These typically had in-house HR services, but occasionally needed more specialist HR skills. This type of work included handling the appointment of senior staff, undertaking HR systems development projects, competency audits and skills needs analysis. Respondent 8, who claimed to do a lot of this work, charged up to $£ 1000$ per day. She claimed to have one client that resulted in over $£ 60,000$ of business and another that resulted in over 100 days' work. Relationships with large clients thus appeared to be very lucrative, and the respondents could also foster symbolic capital, as testimonials could be posted on websites and "bragging rights" could be claimed when networking.

Other work was described as of lower status. Interim contracts, which were individually held and often came from employment agencies (see below), appeared unattractive to many. These contracts, which stipulated working time expectation in terms of days per week and minimum periods of employment, could be particularly time consuming. They were typically for welldefined projects, maternity leave or as cover for long-term illness. Respondent 21 refused to do interim work because it was "like a proper job". Respondent 9 said she only considered interim work if it was "very short term". Three respondents [1, 9 and 15] did mention they took retainers, or regular payments from SME clients which guaranteed a quick response to HR issues over a set period. However, rather than servicing interim contracts themselves, six respondents sought to redistribute any interim contracts they identified within their networks, acting as agent rather than executor. 
Crucially, larger interim contracts could reduce time for business development, and this could be damaging. For example, Respondent 12 took an interim contract as a generalist HR manager with a local firm and this contract 'turned into two and a half years of work'. While this suited him at the time, as he was a single parent, he was struggling to place himself in work at the time of the research. He claimed that the value of his networks had diminished. As delivering large contracts could prevent networking and other business development activities, many consultants had "a level of paranoia", in the words of Respondent 22, about the relationship between paid work and non-paid business development activities, as Respondent 13 also reflected:

It's been feast and famine to a certain extent, but you can see it coming because the diary has a lot of white space and that's the time to either say [names himself], "have you got anything else or do I need to go out and actually do some business development work?"

Respondents also reported that fostering close relationships with clients (12) could create opportunities within that client's network (11). For example, Respondent 17 delivered HR service to one veterinary clinic and then, through this contact, was referred to further contracts with other veterinary clinics. Respondent 22 commented on similar experiences in the tourist industry. Using reflexivity to selectively invest in client relationships (12) appeared to be a key component of respondents' strategies and habitus, as Respondent 14 reflected:

I am very aware that I would try and promote the sort of environments and cultures I've worked in, if I think that's the fit. If it is public sector I do play on my police experience $[\ldots]$ I have just been talking to a manufacturing company $[\ldots]$ they were painting this really bad picture of their rufty-tufty workforce, and so right, let's pull on my experience of manufacturing [...]. So, yes, I would use that and play on it, [however] they are more likely to say yes if someone has recommended me, so I know that those networks are important.

The possibility of more business also led consultants to be reflexive about fees, when they should start to charge clients, and what to charge, as Respondent 7 reflected: 
A lot of it is ad-hoc HR. We call it 'pay-as-you-go' HR, because we don't charge you the same fee, we don't charge a monthly fee, we just [*pauses*] It's not a case of "Right, we press a button, the clock starts ticking," it's a case of, if it's a five-minute conversation, and we just give them a quick answer, then we don't charge them. But if it leads down to a disciplinary where we need to produce documentation, be onsite for a meeting to help dismiss, discipline, whatever, then we'll start charging at that point.

(b) Referral fees were paid when one agent or agency referred another agent to work, or when an 'associate' was invited to work alongside a HR consultant who developed and negotiated a larger contract. Referral fee norms (institution/doxa) ensured the referrer was paid for time investments required to identify opportunities (10), while the person referred to work paid for the opportunity (3). These took various forms. Sometimes the client paid the person who undertook the work, with this referee then sending a percentage of the fee to the referrer. Sometimes the referrer would charge the client and then pay the referee in a separate, if smaller, transaction.

The referral fee system was generally accepted and was, apparently, enforced by the threat of withdrawing commitments (9), as the following quote suggests.

It would be unethical, unprofessional for me to do it privately [i.e. without paying the referral fee] because once I've had a client of an associate then it's not worth it. If the company I'm an associate for found out they might say "well we don't trust you", and that trust is very important [...] They're not going to be passing on the leads to me which are lucrative and keep me busy in work at a good daily rate. They would just say "well we don't want to work with you anymore" (Respondent 8).

Fees varied between $10 \%$ and $50 \%$, and their level appeared to be related to the size, value and type of work referred, although the quality of the relationship between the referrer and the referee also mattered. In some cases, no referral fees would accrue, such as when a trusted friend worked on a large contract with an important client. Lower referral fees of $10 \%$ were typical for a small piece of work referred to a 'friend', or close and trusted associate. Higher fees $(50 \%)$ accrued in the market for training services. Rates in between these extremes were 
also common. For example, Respondent 8 was happy to offer a $30 \%$ referral fee to a law firm because the work referred was with "big clients" who also paid well and bolstered her reputation (symbolic capital).

Outcomes were locally and reflexively contested, depending on changing circumstances, as Respondent 16 reflected:

I did take $10 \%$ on this particular one [a contract she referred to an associate] but we're probably going to be talking about something else now because they want a lot more done [...] $10 \%$ for 12 months' work is not a lot [...] I am going to have that business conversation which basically says it may need to go up. Well, it does need to go up to at least $80 / 20$.

In another example of contested referral fees, Respondent 2 reported that she was working as an associate of a training consultancy. In a conversation with her client, she discovered that the training consultancy (the referrer) was charging that client $200 \%$ more than she received. She requested an increased day-rate, which led to accusations of "unprofessional conduct", because she had openly discussed day-rates with a client. This association, which was clearly based in a shallow connection, ended, with commitments withdrawn (9).

\section{Relational Mechanisms}

Relational mechanisms emerged from distinctive combinations of economic interests and expertise. Two types or classes of relational mechanisms were identified: collective delivery mechanisms and non-competitive exchange mechanisms, with each being associated with a different contractual mechanism. Collective delivery mechanisms pooled contractors to deliver larger contracts to clients $(a)$. Non-competitive exchange mechanisms facilitated referrals and any associated fees $(b)$. Relational mechanisms were thus particular to contractual mechanisms (the economic base).

(c) Collective delivery mechanisms emerged when consultants identified a larger contract that they did not have the skills or capacity (time) to service independently. They could be dyadic, such as when a pair of consultants delivers a contract to a client, or involve larger groups. They could be cooperative relationships $(c+)$ between individuals with similar skills, in which case contracts were for reasons of capacity, or they could be collaborative 
relationships $(c-)$ between consultants with complementary skills, in which case delivery was built on synergies between trades.

An example of cooperation was offered by Respondent 11, a training expert, who had been working with a group of five associates to service a large contract to assess training outcomes for a public-sector organisation. An example of collaboration was described by Respondent 18, a specialist recruiter:

I've been drawn into the project to look at it from a recruitment perspective. [Names small HR firm] is looking at that from the HR legal side of things and, then, somebody else who's a trainer, they provide [...] the training aspects for businesses. So, between the three of us, we're working on something which will generate business for every one of us, but we're working individually on it $[\ldots]$.

In collective delivery mechanisms, consultants worked together (7) and, in the case of cooperation, they typically needed to be engaged in more detailed cultural capital exchanges $(5,8)$ to meet client needs (hence $c+$ ). In contrast, where consultants collaborated, the need for detailed sharing of cultural capital became less, but contractors still needed to exchange information and to establish roles and relations $(6,10$, hence $c$-). Consultants where thus required to be reflexive about the qualities of the contract and the people they worked with, as this would affect interactions (as evidenced below).

(d) Non-competitive exchange mechanisms, in contrast, did not involve working together in delivering work, but outcomes could be identified in terms of social capital relations $(3,6,7$, 10, 11, 12). These mechanisms typically developed between agents with less similar skills sets. Agents could identify opportunities that they were not qualified to deliver, and then pass these to others who had the skills necessary to complete the opportunity identified. In these circumstances, referral fees would often be paid between agents, and this "oiled the wheels" of the market by ensuring opportunities passed through social networks $(10,3)$.

A good deal of reflexive struggle was apparent when respondents identified their own business interests and who would be the 'right' associates to relate to. For example, HR consultants were often referred work by accountants and solicitors, who could not deliver the 
HR work themselves, and so some HR consultants sought to develop social capital with members of these professions (12), hoping to use these relationships to build bridges to clients $(a)$. The employment law specialist (Respondent 1) stood out in this regard. He claimed to acquire $60 \%$ of his work from referrals from accountants, and so he was heavily engaged in networking events which accountants would attend. In another example, Respondent 8 (see above) obtained many of her "big clients" from a corporate lawyer, who was a friend of hers. Ultimately, this dyad (7) profited from the access one could provide to the other $(3,10)$.

These non-competitive exchanges resulted in respondents reflecting on their own abilities, especially when opportunities identified were closer to their own expertise, as Respondent 22 suggested:

You come into an organisation on the back of one particular discipline [...]. "Can you do X for us?" You say "yes" and they come back and say "great, can you do Y", recruitment or whatever [...] If you're not careful, they say: "Well, what bloody hat are you wearing today, then? How many things do you know?" So, on occasions I do say: "Yes, I could have a go at this and I am going to need a lot of time to develop material, which I think you could afford in terms of time, but you might be better off talking to my colleague". And yes, I do make referrals.

Consequentially, and as we see below, respondents were also highly reflexive about the qualities of the organisations through which they were engaged.

\section{Organisations}

The mechanisms were supported in diverse ways by a variety of organisations, which we classified as formal and informal types. Informal organisations were enduring networks of consultants (variously formed) who worked together. They worked together to variously contract with clients, exchange referral fees, deliver work, and exchange opportunities $(a-d)$. Informal organisations were sub-classified as in-groups and associate groups. Whilst, in practice, these distinctions could be difficult to untangle, the distinction has conceptually purposive, as subtypes related to different resources. In-groups pooled HR consultants with similar cultural capital resources. Associate groups pooled a broader range of business agents 
with different but, potentially, complementary cultural capital resources. They were also associated with different depths of social capital, with in-groups pooling greater resources.

Formal organisations conformed more closely to Fleetwood's (2015) definition (above). Respondents identified three types of organisations as having an influence on their practices. First, employment agencies, sought to exploit social capital (10) by extracting fees from clients and contractors (3). Second, network facilitators emerged to develop the consultants' shallow forms of social capital $(10,11,12)$. Third, professional associations developed professional knowledge (embodied cultural capital) and social capital within the regional field $(1,2,5,8,12)$. The following sections detail each of these organisations, the capitals exchanged and developed through them, the institutions they emerge from and the reflexive struggles they invoked in the entrepreneurial agents who engage with them.

\section{Informal organisations:}

In-groups could be identified as deeper relationships among consultants with similar skills. Many consultants described "a handful", "five" or "seven or eight" of such relationships, with these groups typically including several self-employed HR consultants, as well as people from closely related professions, such as training and recruitment. Members of these groups would meet regularly, often to drink coffee, in pairs or small groups, and often around more formally organised networking events (detailed below). These meetings could be used to trade gossip about work-related matters $(5,8)$ and discuss work opportunities $(6,11)$. Where larger contracts were identified, consultants could call on in-group members to help service them (7), and so in-groups could be used to organise cooperative collective delivery mechanisms $(c+)$.

Typically, those with well-developed in-groups had invested in relations with clients (12) as they engaged in contracting with them over time (4), and so they tended not to use in-groups for access to clients $(3,11)$. Instead, these relationships developed based on cultural capital complementarities. Exchanges of cultural capital were habitual (institution/doxa) within ingroups $(5,8)$. Close associates would freely offer advice on various matters, such as "managing taxes", benchmarking fees or insights about the abilities and reputations of others. As Respondent 16 reflected: 
We've got a group now of 8 or 9 of us and the group (...). We use each other as a skills bank, a knowledge bank (...) There was an email came out on Friday, one of us will say "Well, I've got this situation, anybody got any thoughts on it?" Or "I'm thinking of doing this, does this sound right?" Sometimes it can just be work overload.

Maintaining in-groups, however, was not without its existential struggles, as favoured relationships apparently required more self-conscious concealment. For example, where ingroups exchanged opportunities, cooperated in delivery and referred work, potentially for fees $(a-d)$ this could be concealed from the group to maintain mutual reciprocity, as Respondent 9 reflected:

I think we're probably quite discrete in the group about working with each other because somebody might be sitting there thinking “Oh, why didn’t [someone] ask me to do that?" So, I think we're quite discrete about working with each other.

Associate groups increased the potential for agents, who did not compete between themselves for clients, to exchange opportunities $(3,6,10,11)$ and collaborate in offering services to clients $(c-)$. These groups were sometimes quasi-formal organisations. One example was offered by Respondent 19. He owned an SME that, initially, sought to sell HR tools and selfhelp books to SME clients (4, objectified), before then using this initial engagement to sell additional HR services (4, embodied). While he did not employ HR consultants directly, his associates agreed to have their abilities promoted in his website (5), and he then referred work to these consultants when it was identified, collecting a $20 \%$ referral fee when he did so (10).

Respondents appeared to be highly reflexive about the qualities of their in-group and associate group relations. These relationships were based on complex histories, in which the perceptions of ability (cultural capital) and trustworthiness (symbolic capital) were considered, as Respondent 16 reflected:

There was a likeness of approach amongst those people whom I call my close colleagues [and thus work with]. There was a way of working that was very similar in 
your ethics; in your business ethics [...] Well, I don't believe in anybody that wants to take the piss [sic]. I don't believe in anybody that takes a load of money for doing work that they haven't really done (Respondent 16).

Consultants could talk up the quality of their own in-groups and associations, and they could also be disparaging about the reputations of others' networks, as Respondent 14 reflected:

I know there are a couple of people who are in networks who don't have a good reputation, and that's not just my view. There are a couple of names which would be mentioned in my little circle [and you'd get] a few sniggers. It's like, "oh beware, you're not thinking of working with them, are you?"

It thus appears that an ongoing reflexive struggle, involving the promotion and guarding of the qualities of one's own associations, was an important part of 'the game'.

\section{Formal organisations}

Employment agencies had concerns which competed with the interests of the respondents. These agencies developed or exploited weaker forms of social capital to extract economic capital from HR consultants $(b)$, functioning as labour market intermediaries to place HR experts in interim contracts. However, and as we saw above, the interim contracts they offered were typically viewed unfavourably.

The training market appeared untypical. Both respondents who were training specialists confessed to being engaged by training agents (3). Training contracts were typically relatively discrete, involving one day or a few days of a specific type of training for a specific client, so these contracts tended to be short-term, whether they were 'self-generated' or provided by an agency. Engaging through an agency thus offered considerable time-savings as clients did not need to be identified, courted and obtained.

Given that referral fees could be comparatively large (see above), Respondent 2 was critical of the practices of training agencies, which she described as undermining the market:

So, they have a big group of associates that work for them for a daily rate, and they find the business [...] I went to work [*pauses*] went to meet this particular guy who 
scours people's websites. Looks for testimonials $[\ldots]$ and then contacts those companies [...] He'll say "Oh, who are you dealing with?" And he'll ring them and says he'll undercut them. It goes on all the time, but there's a few of us that have got ethics and won't do that.

Unsurprisingly, the existence of larger competitors and employment agencies made the consultants consider their own fees, and to be reflexive about how they competed, as Respondent 3 suggested:

We want to charge something that's reasonable, that we all feel comfortable with, that's reasonable, and we know that some of the large consultancies charge three, four, five times as much as we might.

Networking facilitators sought to support or develop the social capital of the respondents in return for fees $(3,10)$. These included local Chambers of Commerce (henceforth Chambers) and "Netco" (a pseudonym), a private-sector firm. There were two branches of Chambers operating in the region, and these offered a variety of events, typically around meal times, where respondents could network. Some suggested the Chambers' events were of limited usefulness, as Respondent 5 reflexively opined:

You know, if you go to a Chamber of Commerce networking lunch, you know, it's predominately male accountants and solicitors selling each other goodness knows what, in a relatively aggressive fashion and most of the HR people I've spoken to, male and female, sort of shy away from that way of doing things.

However, as accountants and solicitors were often reliable sources of referrals $(d)$, others, such as Respondent 1, found these events useful. Respondent 19 also found the Chambers meetings useful for developing his associate group $(f)$.

About half the respondents had, at one time or another, tried to connect with work opportunities through Netco. This fee-taking private-sector firm $(3,10)$ organised members into closed or artificially bonded "cells" that each contained only one member of any profession or trade. Cell members would meet for breakfast, weekly, with each cell member 
having an obligation to refer work $(a)$ to other cell members. Netco membership thus encouraged more active information exchange between trades-people who were not in competition $(d)$.

Some respondents viewed Netco favourably, and valued this closed social structure. Respondent 9, who acquired 'the majority' of her work from Netco, confessed:

I do like efficiency [...] the key phrase for me was "We'll teach how joining [Netco] can lock out your competitors" and I thought, "Right, there's two other people in the room, who do what I do, and they're my competitors. So, I'm going to sign up and join this group, here, and I'm going to lock them out." And I literally made out my application in the middle of the meeting.

Others, however, were more disparaging about the qualities of Netco's referral system:

What [Netco] stands for is that I must refer you because you're the accountant [...]. I don't necessarily want to do that because unless I've worked with you as an accountant I don't know your nature of work. I also find it slightly insular [...]. If I joined [Netco] and I am a HR consultant, that stops other HR consultants joining it, and [...] I didn't want to do that (Respondent 16).

The value and status of network support organisations was thus a matter of reflective debate and, since forms of affiliation affected perceptions of legitimacy (symbolic capital), respondents appeared keen to talk up the virtues of their way of developing business, and deride those organisations that operated with institutions/doxa (norms, values, etc.) that were different from their own.

\section{Professional associations}

The third and final group of organisations discussed here comprises those which sought to develop professional knowledge (embodied cultural capital) and social capital within the regional field. As well as the UK Government, which freely offers information ( 6 ) about how to set up as a self-employed trader or SME enterprise, the CIPD and a local HR Directors' Forum were important fee-taking organisations which (i) supported professional practice in 
HR (1); (ii) and provided networking opportunities to develop relationships with HR consultants and potential clients $(a-e)$.

The CIPD makes money in the form of fees for membership (3) and HR-related products (1). Importantly, the CIPD achieved a 'Royal Charter' in 2000, and, since then, becoming a 'Chartered' member requires demonstration of experience in professional practices at a level equivalent to a Master's-level degree, and so membership conferred symbolic capital. All but a handful of respondents had, at one time or another, been members of the CIPD, although a few consultants with established business had let their affiliations subsequently lapse. Importantly, the CIPD also requires members to engage with continuous professional development, and its fees provided access to a regular timetable of events, such as employment law updates or introductions to new tools and technologies, which supported professional development (1). These events, which were organised through regional branches in an equivalent way to Chambers, were a good opportunity to meet with and develop ingroup relations $(e)$ and to network with clients $(12,4)$.

Five respondents also sought to raise their profiles, or increase their symbolic value, by acting as organisers of local branch events. While some were adamant that their involvement in the CIPD was only about professional development (1), these CIPD organisers were acutely aware that their profiles were raised by participation in the local branch, as Respondent 3 suggested:

Whereas some people go to networking and they hand out their cards all the time, I've deliberately not gone down that route with CIPD [...] that wasn't ever my reason for being on the Committee or going to CIPD events [...]. [However] I might have been writing the newsletter on a regular basis, my name might have been there. I haven't proactively said I'm looking for work because of it, but people are aware of me in that network.

To contract with larger clients, consultants had to foster closer relationships with senior staff from these organisations (12). Networking through a monthly HR Directors Forum, at which senior HR practitioners would meet to discuss HR issues and problems, was said to be more useful for this activity. This group was more exclusive, as members had to have Directorlevel experience in HR to receive an invite, and so it was not open to all. 
Arguably, attendance at networking events became a persistent (doxic) habit for these consultants, and the evidence suggested that they were obligated to attend networking events regularly to benefit from the resources they contained, as Respondent 19 suggested:

[The HR Directors' forum] does create leads, but it creates leads from people who have seen you around. It goes back to that they have to know you, have to like you, have to trust you. They've seen you around and you have to make sure that you are seen around [...] Once people start to think that you've got contacts or you know people, then they will start to come to you (Respondent 19).

Failure to regularly attend networking events could limit one's opportunities, as one respondent succinctly suggested: "if you are a bit more peripheral then, sometimes, [attending a networking event] can be a bit of a waste of time" (Respondent 25). However, and whilst poor levels of participation in networking events was seen to be a problem (see also Vincent, 2016), the values and practices on display when networking were also consistently contested:

I know some people who exploit and that really annoys me, some people - I call them 'professional networkers' - who get themselves into every group going, every time you turn up at a meeting, they're there. They have their business cards at the ready and you see them working the room, and I just think "you don't have to do that". People will get to know what you do and if they think you're credible (Respondent 14).

\section{Discussion: Entrepreneurial agency and field relations}

The analysis undertaken here reveals the field as a hierarchically organised causal assemblage that supported the careers of our respondents in many ways. It was rooted in the economic necessities of the market (contractual mechanisms and fiscal means), to which the relational mechanisms the respondents enacted and adapted, and which various forms of organisation, then, variously supported. Ultimately, these field elements had specific powers, which emerged from the species of capital that the respondents developed and traded, and which transformed resources and relations as agents were engaged with them. 
Respondents had various strategies for engaging with the field elements identified. Some respondents chose to pursue a wide range of SME clients. Others devoted time and energy to pursuing larger clients, because these were prestigious and paid well. Some sought to derive a substantial part of their income from referral fees by acting as labour market intermediaries. These choices affected the relations, mechanisms and organisation through which they were engaged with work. However, consultants often obtained income from a mixture of these sources, adapting their approaches to reflect their preferences and the field's present opportunities, and so the field offered rich opportunities that could support different consultants in diverse ways. They could develop cultural capital by investing time and money engaging with the CIPD. A diversity of social capital was available at various times and various places, and this social capital could be exchanged for economic capital in various forms. These consultants thus had a variety of choices and could progress their career interests in many ways. Overall, while it was possible to point to winners and losers, with gender playing a significant role in affecting outcomes (see Vincent, 2016), the constitution of this field appears to be robust in that it supported different approaches to doing business.

Arguably, as this will not be the case for all fields (see Woolcock and Narayan, 2000), the type of mapping and categorical work undertaken in this paper may be of more critical significance in other settings, in which entrepreneurial actors may lack appropriate means to develop the resources needed to subside. Consequentially, RBA might enable (i) contributions to policy debates around regional economies (see Woolcock and Narayan, 2000; Westlund and Bolton, 2003; Bebbington, 2007; Vershinina et al., 2011; Spigel, 2013) by identifying the range of support organisations and mechanisms that exist and, potentially, spot gaps in provision that might limit entrepreneurial careers. Unfortunately, as this study was limited to respondents who managed to sustain their self-employed and entrepreneurial careers, the data offers few examples of unfulfilled ambitions (cf. Vincent, 2016). We can note that those (more typically women) who engaged extensively with referral fee payments, intern contracts and training agencies appeared to be at a disadvantage (ibid.), but engaging with such contracts could be attractive as this type of work was comparatively easy to find.

Arguably, the form of analysis undertaken here, which initially identified the field elements that agents were practically engaged with before assessing these field elements in terms of the resources they contained, can be repeated for other types of economic actor in other fields. This form of analysis is likely to be particularly relevant to geographically informed analysis 
of entrepreneurship and studies in regional development. These disciplines are concerned with identifying and potentially supporting economic development, and the method extended here facilitates the identification (and absence) of opportunities to trade on specific forms of capital. Arguably, forms of comparative institutional analysis, which might use Realist Bourdieusian Analysis to study dissimilar groups in the same setting or compare outcomes for similar groups in different settings, is likely to be particularly good for identifying the causes of relative (dis)advantage, and a previous contribution (Vincent, 2016) offers a rudimentary example.

Our analysis was also directed at (ii) our understanding of the lived experiences of skilled self-employed workers in a networked society (see Castells, 1996; Wittel, 2001). The respondents were complicit and instrumental in using social connections to get ahead, and using different sorts of people to get ahead in numerous ways. These respondents' experiences and deportments appeared analogous with affective conjuring or shape-shifting. Respondents appeared to transform the qualities of relations and relationships to maintain appearances and/or to further specific interests. They reflected and engaged with different and, at times, contradictory personas in different settings. They were engaged scholars within the CIPD. They were active network exploiters in Netco. They were accomplices in associate groups. They were the caring friend in in-groups. They were dedicated suppliers in contractual mechanisms. They could not be all these things at once, but they did not need to be, because specific places demanded specific personas. They had to represent themselves in diverse ways at various times and in various places, with this variance being directly affected by the forms of resources (forms of capital) that were accessed and transformed in different field elements: each had their own normative basis, rooted in the resources and relations these implied, and so the identification of this normative variety, and its corresponding resourcebased antecedents, adds richness to our understanding of habitus that would be absent without affective means to unpack field elements.

Their performances on these various stages were also not uncontentious. Those with developed in-groups could be depicted as cronies, while those who developed and benefited from large associate groups could be cast as exploitative. Entrepreneurial reflexivity thus appeared to require engagement with a geographically organised world of normative struggle in which their work was experienced in terms of the ongoing process of validating their own approach to practice. These findings confirm Archer's (2010) view that reflexivity is essential 
in situations where competing logics exist (see also De Clercq and Voronov, 2009), or where no standard normative template can be assumed as always appropriate to specific situations.

However, there were also specific institutions that were appropriate or germane to the field elements with which our respondents were engaged. They were constitutive of the doxa of the setting, relating to what was or was not "proper conduct" within field elements observed, even if these norms could also be reflexively contested. As such, these findings suggest that Bourdieu's approach (see Bourdieu and Wacquant, 1992), in which reflexivity is apparent in the art of the deployment and contest of habitus, holds firm. Reflexivity and more subconscious/impulsiveness action are thus both personal and situational. Whilst some CR scholars view these matters as distinct: "the proportional contribution of habitus and reflexivity vary systematically with the order or reality in question" (Archer, 2012:76, emphasis in original), such distinctions are, arguably, difficult to make in practice. In our formulation, habitus is constituted of reflexivity, subconscious action, and the connective tissue of conceptual phenomena that link affectivity, via 'deep' or tacit understanding and conceptual knowledge, and then to the forms of inner-conversation, communication and dialogue that are appropriate to the setting.

\section{Conclusion}

The analysis presented in this paper confirms that taking Bourdieusian scholarship towards CRS results is analytically beneficial. Whilst the field is a relatively mute category in existing Bourdieusian research on entrepreneurial careers, when taken towards CRS, the field (viz laminated system), becomes a vibrant and deep category that roots our understanding for forms of capital in middle-range phenomenon (field elements), that then also provides novel insights into agents' reflexive struggles within fields. As such, this paper also contributes a new and potentially useful form of analysis, along with others who combine Bourdieusian and realist analytical categories (see Sayer, 2005; Elder Vass, 2010).

Arguably, once the elements of Bourdieu's field theory are broken down in terms of its ontologically heterogeneous elements, it appears becomes compatible with CRS. Equally, when Fleetwood's (2015) CRS-informed taxonomy is analysed in Bourdieusian terms, as constituted of forms of capital, the causal powers and potentials of the middle-range phenomena it identifies (social structures, organisation, mechanism and institutions) are also 
rendered more obvious and vivid. As such, we can conclude there is ample grounds for mutual learning and exchange between communities of scholars engaged with CRS and Bourdieusian forms of analysis.

The paper has contributed methodologically by developing a novel analysis of the anatomy of the field studied, and the ways in which actors were both engaged with and constitutive of it. The methods section of the paper highlighted essential similarities between Bourdieusian scholarship and CRS. Both appeared to concur: analysis should move through characteristics of the field (viz laminated system), the qualities of their identifiable elements, and how specific agents are engaged with them. In this paper, we identified field elements in terms of their essential structure or form by: (1) engaging with the various resources they contain; (2) identifying their doxa or rule systems, and how these conditioned (1); before (3) exploring how agents were differently engaged in reflexive struggles as they competed for the resources they contained. Arguably, and in line with CRS, such analysis facilitates finer grained appreciation of both the parts of society and the people it contains without conflating one with the other.

As we saw in the discussion, this form of analysis enabled critical reflection on the constitution of the field studied, specifically, in terms of the range of resources made available to the class of agent (HR consultant) and how this conditioned (without determining) respondents' experiences of work (see also Vincent, 2016). Arguably, this study, which focused on one class of respondent in one field, is somewhat limited: comparative institution assessments of diverse groups in the same or distinct settings are likely to throw up critical distinctions that merit or suggest specific policy or practical interventions. However, to the extent that Realist Bourdieusian Analysis has been more fully fleshed-out and defined within the context of this paper, the theoretical and methodological developments we suggest reveal new points of analytical departure and a novel approach to the study of complex social formations in which agents compete, entrepreneurially or innovatively, for resources. 


\section{References}

Adams T and Demaiter E (2008) Skill, education and credentials in the new economy: the case of information technology workers. Work, Employment and Society 22(2):351362.

Adler P and Kwon S (2002) Social Capital: Prospects for a New Concept. Academy of Management Review 27(1): 17-40.

Anderson A and Miller C (2003) "Class matters": human and social capital in the entrepreneurial process. Journal of Socio-Economics 32(1): 17-36.

Archer M (2003) Structure, Agency and the Internal Conversation. Cambridge: Cambridge University Press.

Archer M (2010) Routine, Reflexivity and Realism. Sociological Theory 28(3): 272-303.

Archer M (2012) The Reflexive Imperative in Late Modernity. Cambridge: Cambridge University Press.

Barley S and Kunda G (2004) Gurus, Hired Guns and Warm Bodies: Itinerant Experts in a knowledge Economy. Princeton: Princeton University Press.

Bebbington A (2007) Social capital and development studies II: can Bourdieu travel to policy? Progress in Development Studies 7(2): 155-162.

Bhaskar R (1979) The Possibility of Naturalism, Brighton: Harvester Press.

Bhaskar R (1993) Dialectic: the Pulse of Freedom, London: Verso

Bhaskar R (2008) A Realist Theory of Science, London: Verso.

Bourdieu P (1977) An Outline of a Theory of Practice, Cambridge: Cambridge University Press

Bourdieu P. (1984) Distinction: a social critique of the judgement of taste, Cambridge, Mass.: Harvard University Press.

Bourdieu P. (1985) The Social Space and the Genesis of Groups. Theory and Society 14: 723744.

Bourdieu P (1986) The forms of capital. In Richardson J (ed.) Handbook of Theory and Research for the Sociology of Education. New York: Greenwood Press. 241-58.

Bourdieu P. (1989) Social Space and Symbolic Power. Sociological Theory 7: 14-25.

Bourdieu P (1990) The Logic of Practice. Cambridge: Polity Press.

Bourdieu P. (1994) In Other Words: Essays Towards a Reflexive Sociology, Cambridge: Polity Press.

Bourdieu P (2005) The Social Structures of the Economy. Cambridge: Polity Press. 
Bourdieu P and Wacquant J (1992) An invitation to Reflexive Sociology. Cambridge: Polity Press.

Burt R (2005) Brokerage and Social Closure: An Introduction to Social Capital. Oxford: Oxford University Press.

Castells M (1996) The Rise of the Network Society, The Information Age: Economy, Society and Culture. Oxford: Blackwell.

Cattell V (2004) 'Having and Laugh and Mucking in Together: Using Social Capital to Explore Dynamics Between Structure and Agency in the Context of Declining and Regenerated Neighborhoods', Sociology, 28(5): 945-963.

Coradini O (2010) The divergences between Bourdieu's and Coleman's notions of social capital and their epistemological limits. Theory and Methods 49(4): 563-583.

De Clerq D and Honig B (2011) Entrepreneurship as an integrating mechanism for disadvantaged persons. Entrepreneurship \& Regional Development 23(5-6): 353-372.

De Clercq D and Voronov M (2009) Towards a Practice Perspective of Entrepreneurship: Entrepreneurial Legitimacy as Habitus. International Small Business Journal 27(4): 395-419.

Drakopoulou-Dodd S, McDonald S, McElwee G and Smith R. (2014) A Bordieuan Analysis of Qualitative Authorship in Entrepreneurial Research. Journal of Small Business Management 52(4): 633-654.

Edwards P, O’Mahoney J and Vincent S (eds) (2014) Studying Organizations Using Critical Realism: A Practical Guide, Oxford: Oxford University Press.

Elder Vass D (2010) The Causal Power of Social Structures: Emergence, Structure and Agency. Cambridge: Cambridge University Press.

Fleetwood S (2015) From Labour Market Institutions to an Alternative Model of Labour Markets. Forum for Social Economics 46(1): 78-103.

Glaser B and Strauss A (1967) Discovery of Grounded Theory: Strategies for Qualitative Research, New York (US): Aldine.

Goddard, A. (2004) 'Budgetary practices and accountability habitus: A grounded theory', Accounting, Auditing and Accountability, 17(4): 543-577.

Granovetter M S (1973) The Strength of Weak Ties. The American Journal of Sociology 78 (6): 1360-1380.

Hodgson G (2006) What are Institutions? Journal of Economic Issues 40(1): 1-25.

Jenkins, R. (2002) Pierre Bourdieu, London: Routledge. 
Karataş-Özkan M (2011) Understanding relational qualities of entrepreneurial learning: Towards a multi-layered approach. Entrepreneurship \& Regional Development 23 (910): 877-906.

Kempster, S. and Perry, K. (2014) 'Critical Realism and Grounded Theory'. In Edwards P K, O’Mahoney J and Vincent S (eds) Studying Organizations Using Critical Realism: A Practical Guide. Oxford: Oxford University Press, 86-108.

Lee R and Shaw E (2016) ‘Bourdieu's non-material forms of capital: Implication for start-up policy', Government and Policy, 0(0): 1-15.

Lepak D and Snell S (1999) The Human Resource Architechture: Towards a Theory of Human Capital Allocation and Development. Academy of Management Review 24(1): 31-48.

Lin N (2008) A Network Theory of Social Capital. In Gastiglione D, van Deth J and Wolleb G (eds) Handbook on Social Capital. Oxford: Oxford University Press, 50-69.

Malecki E (2012) Regional Social Capital: Why it Matters. Regional Studies 46(8): 10231039.

Marlow S and Carter S (2004) Accounting for Change: Professional Status, Gender Disadvantage and Self-Employment. Women in Management Review 16(1): 5-16.

Nowicka M (2013) Positioning strategies of Polish entrepreneurs in Germany: Transnationalising Bourdieu's notion of capital. International Sociology 28(1): 29-47.

O'Mahoney, J. (2012) 'Embracing essentialism: a realist critique of resistance to discursive power', Organization 19(6): 723-741.

Özbilgin M and Tatli A (2005) “Book review essay: Understanding Bourdieu's contribution to organisation and management studies". Academy of Management Review, 30: 855877.

Putnam R (2000) Bowling Alone: The Collapse and Revival of American Community. New York: Simon and Schuster.

Sallaz JJ and Zavisca J (2007) Bourdieu in American sociology, 1980-2004, Annual Review of Sociology 33: 21-41.

Sayer A (2005) The Moral Significance of Class. Cambridge: Cambridge University Press.

Scott M (2012) Cultural entrepreneurs, cultural entrepreneurship: Music producers, mobilising and converting Bourdieu's alternative capitals. Poetics 40: 237-255.

Shaw E, Gordon J, Harvey C and Maclean M (2011) Exploring contemporary entrepreneurial philanthropy. International Small Business Journal 31(5): 580-599. 
Spigel B (2013) Bourdieusian approaches to the geography of entrepreneurial cultures. Entrepreneurship \& Regional Development, 25(9): 804-818.

Stake R (2006) Multiple Case Study Analysis. London: Guildford Press.

Sutherland L and Burton R (2011) Good Farmers, Good Neighbours? The Role of Cultural Capital in Social Capital Development in a Scottish Farming Community. Sociologia Ruralis 51(3): 239-255.

Thwaites L and Jennsion P (2006) HR Benchmarker 2006: HR Performance Indicators. London: DLA Piper.

Vershinina N, Barrett R and Mayer M (2011) Forms of capital, intra-ethnic variation and Polish entrepreneurs in Leicester. Work, Employment and Society 25(1): 101-117.

Vincent, S. (2005) 'A Transmutation theory of inter-organizational relations and networks: Applying critical realism to analysis of collective agency', Human Relations, 61(6): 875-899.

Vincent S (2016) Bourdieu and the gendered social structure of working time: A study of self-employed human resources professionals. Human Relations 69(5): 1163-1184.

Vincent S and Wapshott R (2014) Critical Realism and the Organizational Case Study: A Guide to the Discovery of Institutional Mechanisms. In Edwards P K, O’Mahoney J and Vincent S (eds) Studying Organizations Using Critical Realism: A Practical Guide. Oxford: Oxford University Press, 148-167.

Westlund H and Bolton R (2003) Local Social Capital and Entrepreneurship. Small Business Economics 21(2): 77-113.

Williamson O (1986) Economic Organization: Firms, Markets and Policy. Hemel Hempstead: Harvester Wheatsheaf.

Wittel A (2001) Towards a Network Sociality. Theory, Culture and Society. 18(6): 51-76

Woolcock M (1998) Social Capital and Economic Development: Towards a Theoretical Synthesis and Policy Framework. Theory and Society 23(2): 151-208.

Woolcock M and Narayan D (2000) Social Capital: Implications for Development Theory, Research and Policy. The World Bank Research Observer 15(2): 225-249. 
Table One: A key to forms of capital exchange/development

\begin{tabular}{|c|c|c|c|c|}
\hline & Economic Capital & Cultural Capital & Deep Social Capital & Shallow Social Capital \\
\hline Economic Capital & & $\begin{array}{l}\text { Buying access to new } \\
\text { skills and products ( } 1 \text { ) }\end{array}$ & $\begin{array}{l}\text { Investing in/with } \\
\text { Friends (2) }\end{array}$ & Paying for access (3) \\
\hline Cultural Capital & $\begin{array}{l}\text { Selling abilities and } \\
\text { goods (4) }\end{array}$ & & $\begin{array}{l}\text { Providing valuable } \\
\text { cultural "gifts" (5) }\end{array}$ & $\begin{array}{l}\text { Providing information } \\
\qquad(6)\end{array}$ \\
\hline Shallow Social Capital & $\begin{array}{l}\text { Profiting from access } \\
\qquad(10)\end{array}$ & $\begin{array}{l}\text { Receiving information } \\
\text { (11) }\end{array}$ & $\begin{array}{l}\text { Interpersonal } \\
\text { investment (12) }\end{array}$ & \\
\hline
\end{tabular}


Table Two: A Realist Bourdieusian Analysis

\begin{tabular}{|c|c|c|c|c|c|}
\hline \multicolumn{3}{|c|}{ Field elements } & Forms of capital & Institution/doxa & Emergent reflexive struggles \\
\hline \multirow{4}{*}{ 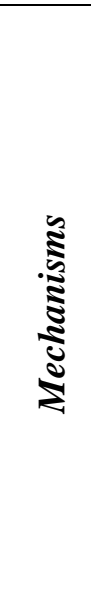 } & \multirow{2}{*}{ 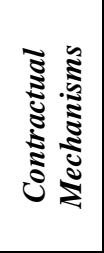 } & $\begin{array}{l}\text { Contracting with } \\
\text { clients (a) }\end{array}$ & $\begin{array}{l}\text { Cultural capital exchanged for economic, and vice versa (4). } \\
\text { Identified as economic base of contractor-client relations, which could also result in } \\
(11,12)\end{array}$ & $\begin{array}{l}\text { Contractual norms (day rates, time- } \\
\text { periods, retainers) } \\
\text { Fostering client relations }\end{array}$ & $\begin{array}{l}\text { How much to charge? } \\
\text { How long to work with one client? } \\
\text { Which contracts to target? }\end{array}$ \\
\hline & & Referral fees (b) & $\begin{array}{l}\text { Social capital exchanged for economic, and vice versa }(3,10) \\
\text { Identified as economic base of referrer-referee relations }\end{array}$ & Contractual norms (percentages) & What size of referral fee? \\
\hline & \multirow{2}{*}{ 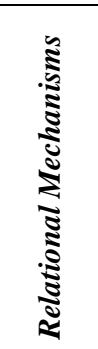 } & Collective delivery (c) & $\begin{array}{l}\text { Economic capital extracted from cultural capital relations, facilitating (a), but based } \\
\text { on ( } 7) \text { - social capital depth between contractors depends on level of cultural capital } \\
\text { they exchange as they serve the client (c+ or c-) } \\
\text { Identified in terms of an economic base of (multi)contactor-client relations. }\end{array}$ & Cooperation (c+)/collaboration (c-) & $\begin{array}{l}\text { Who to work with? } \\
\text { Is my in-group adequate? }\end{array}$ \\
\hline & & $\begin{array}{l}\text { Non-competitive } \\
\text { exchanges (d) }\end{array}$ & $\begin{array}{l}\text { Cultural capital differences enabling weak social capital developments - as } \\
\text { encouraged by economic base (b) } \\
\text { Identified as cooperation in identifying clients between economic agents in adjacent } \\
\text { markets. }\end{array}$ & Collaboration & $\begin{array}{l}\text { Who to work with? } \\
\text { What is my core competence? } \\
\text { Do I have the right associates? }\end{array}$ \\
\hline \multirow{5}{*}{ 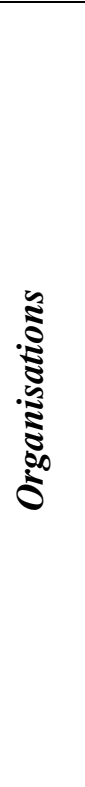 } & \multirow{2}{*}{ 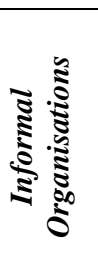 } & In-groups (e) & $\begin{array}{l}\text { Deep social capital between relatively homogeneous consultants, facilitating (a-d) } \\
\text { Identified as similarly skilled individuals }(\mathrm{c}+) \text { helping one another in a variety of } \\
\text { ways. }\end{array}$ & $\begin{array}{l}\text { Gift exchange } \\
\text { Concealing strength of key ties }\end{array}$ & $\begin{array}{l}\text { Who to work with? } \\
\text { How do I maintain reciprocity whilst } \\
\text { competing? }\end{array}$ \\
\hline & & Associate groups (f) & $\begin{array}{l}\text { Deep social capital between relatively heterogeneous consultants, facilitating (a-d) } \\
\text { Identified as differently skilled individuals (c-) helping each other in a variety of } \\
\text { ways. }\end{array}$ & $\begin{array}{l}\text { Opportunity development (via cross } \\
\text { selling) }\end{array}$ & How do I know who to trust? \\
\hline & \multirow{3}{*}{ 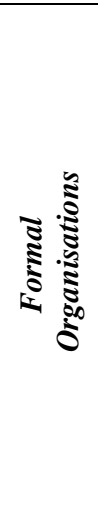 } & Employment agencies & $\begin{array}{l}\text { Organisations seeking to use weak social capital to extract (b) } \\
\text { Identified as organisations operating in the market who identify but do not service } \\
\text { clients. }\end{array}$ & Network exploitation & $\begin{array}{l}\text { Whether to avoid? } \\
\text { How to compete? }\end{array}$ \\
\hline & & Networking facilitators & $\begin{array}{l}\text { Organisations seeking to develop relatively shallow forms of social capital for fee- } \\
\text { paying organisational members (e.g., Chambers of Commerce, Netco) - facilitates (d, } \\
\text { f) } \\
\text { Identified as organisations that seek to bring diverse business interests together to } \\
\text { facilitate novel social capital "bridges". }\end{array}$ & Persistent participation & $\begin{array}{l}\text { Are these organisations personally useful? } \\
\text { Are the values of these organisations } \\
\text { complementary or competitive? }\end{array}$ \\
\hline & & $\begin{array}{l}\text { Professional } \\
\text { associations }\end{array}$ & $\begin{array}{l}\text { Organisations seeking to foster cultural and social capital development (e.g., CIPD, } \\
\text { HR Directors Forum) - facilitates (a-e). } \\
\text { Identified as organisations that bolster and develop cultural capital across fields to } \\
\text { facilitate generalised trust (social capital) }\end{array}$ & $\begin{array}{l}\text { Persistent participation } \\
\text { Communities of practice/learning } \\
\text { norms }\end{array}$ & $\begin{array}{l}\text { Whether or how to use these organisations to } \\
\text { promote self-employed interests? }\end{array}$ \\
\hline
\end{tabular}

